\title{
Epistemologia das artes cênicas: interfaces entre teoria pedagógica e prática escolar
} Epistemology of the performing arts: interfaces between pedagogical theory and school practice

Lisinei Fátima Dieguez Rodrigues ${ }^{1}$ Marta Isaacsson ${ }^{2}$ 


\section{Resumo}

Este trabalho surgiu do questionamento sobre a forma como a docência em artes cênicas na educação básica apresenta-se a partir dos documentos oficiais, tais como súmulas, currículos e programas de ensino. Ao trazer a epistemologia das artes cênicas como conceito operatório buscou-se analisar teorias de currículo e práticas escolares. Incluiu-se nesse cenário alusões aos processos formativos em arte trazidos pelas Leis de Diretrizes e Bases da Educação Brasileira, por documentos como os Parâmetros Curriculares Nacionais e a Base Nacional Comum Curricular. Por considerar que essas diferenças constituem alterações que provocam mais do que ajustes nos tempos e espaços para a aprendizagem, procurou-se identificar de que forma essas configurações impõem-se como epistemologia para as artes cênicas na escola.

Palavras-chave: Artes cênicas; epistemologia das artes cênicas; educação básica; Currículo; legislação educacional

\section{Abstract}

This work arose from the questioning of how teaching in the performing arts in basic education is presented from the official documents, such as summaries, curricula and teaching programs. Bringing the epistemology of the performing arts as operative concept sought to analyze curriculum theories and school practices. Included in this scenario were allusions to the formative processes in art brought by the Laws of Education and Bases of Education, to documents such as the National Curricular Parameters and the National Basic Curricular. Considering that these differences constitute changes that provoke more than adjustments in the times and spaces for learning, we tried to identify in what form these configurations impose themselves as epistemology for the performing arts in the school.

Keywords: Performing arts; epistemology of performing arts; basic education; curriculum; educational legislation 
Os desafios da docência em artes cênicas no contexto da escolarização formal no Brasil são inúmeros e diversos, especialmente quando se pensa na educação em arte como disciplina obrigatória no currículo da Educação Básica. A motivação para este trabalho partiu da necessidade de pensar sobre a docência em artes cênicas definidas pelos documentos oficiais e pelos discursos sobre sua epistemologia. Questionando-se assim, como a pedagogia das artes cênicas está expressa na redação das súmulas, dos currículos e dos programas de ensino.

Parte-se da premissa que a instrumentalização que os docentes necessitam para exercerem seu ofício agrega teorias e práticas que produzem discursos, não apenas em relação à natureza do campo do conhecimento artístico como na forma de abordá-lo. Quando se pensa na ampla faixa etária de estudantes, da educação infantil ao ensino médio, participando de forma obrigatória dessas ações de ensino-aprendizagem, é possível compreender a complexidade da docência em artes cênicas na escola e, por conseguinte, da descrição da especificidade dessas ações.

Ainda que a atividade de modelar planejamentos institucionais possa parecer pouco interessante quando comparada ao fazer artístico, reduzir a importância da sua elaboração fragiliza a visibilidade das artes cênicas como área de produção de conhecimentos. Além disso, possibilita que profissionais não capacitados para a docência no campo da arte definam suas diretrizes epistemológicas.

A sistematização, o registro e o planejamento de ações de ensino-aprendizagem pode tornar única a experiência de criação na escola quando esse trabalho parte do especialista na educação em arte. Uma obviedade que precisa ser repetida com frequência diante das alterações súbitas que ocorrem nas legislações educacionais brasileiras. $O$ encontro entre os estudantes e seus professores pode proporcionar um engajamento que converte a experiência da sala de aula em um espaço privilegiado para a formação artística. Engajamento esse que pode tornar transgressor um espaço que, na maior parte das vezes, se caracteriza pela regulação, contenção e reconstituição de padrões sociais que não acolhem as divergências.

Contudo, para que os processos de criação ocorram e ganhem a devida visibilidade, o docente necessita se apropriar de todas as implicações que sua presença acarreta no ambiente escolar. A compreensão do estado da arte da docência na escola precisa integrar ao repertório do professor de teatro o conhecimento pedagógico específico da educação básica aliado ao conhecimento artístico. Essa afirmativa ainda precisa ser constantemente lembrada, porque a tarefa de compartilhar o tempo e o espaço de aulas com os estudantes é bem mais sedutora do que o envolvimento com os "rituais" escolares.

Levando em consideração tal panorama, optou-se por trazer a epistemologia das artes cênicas na acepção de Wladilene de Sousa Lima, a fim de elaborar um comparativo entre teorias de currículo e práticas escolares. Ao abordar a teoria de currículo na visão de Tomaz Tadeu da Silva e o discurso de práticas escolares implícitas nos conceitos de "currículo integrado, interdisciplinaridade e transdisciplinaridade", através dos estudos de Ivani Fazenda, Joanez Aires, Maria José de Vasconcellos, Marilce Rodrigues e Basarab Nicolescu, acredita-se na possibilidade de disponibilizar uma reflexão teórica sobre o tema da arte na escola. 


\title{
Epistemologia das Artes Cênicas
}

A origem do conceito "epistemologia" remonta aos vocábulos gregos de logos, discurso, e episteme, ciência. Assim, episteme associada a logos pode ser compreendida como "discurso da ciência", sendo um ramo da filosofia que traz a natureza, as etapas e os limites do conhecimento humano. As origens, a historicidade e as formas de ser e de acessar o conhecimento complementariam suas possibilidades semânticas. Nas palavras de Tesser (1994, p. 92), "Epistemologia: é a ciência da ciência. Filosofia da ciência. É o estudo crítico dos princípios, das hipóteses e dos resultados das diversas ciências. É a teoria do conhecimento". Ainda sobre a semântica do conceito de epistemologia, o autor traz as seguintes ideias:

\begin{abstract}
A tarefa principal da epistemologia consiste na reconstrução racional do conhecimento científico, conhecer, analisar, todo o processo gnosiológico da ciência do ponto de vista lógico, linguístico, sociológico, interdisciplinar, político, filosófico e histórico. O conhecimento científico é provisório, jamais acabado ou definitivo. É sempre tributário de um pano de fundo ideológico, religioso, econômico, político e histórico.
\end{abstract}

Ao considerar que as artes cênicas possuem a sua forma própria de produção de conhecimento, cabe ver o que Lima $(2012$, p. 4) propõe como epistemologia inventiva para as artes cênicas:

[...] construção processual do conhecimento; contextualização cultural-política do conhecimento; perspectiva da incerteza e da busca na aventura do conhecer: Lógica da descoberta, em detrimento da lógica da prova; ótica da complexidade, a exigir transdisciplinaridade e articulação de saberes; diálogo crítico/interlocução entre diferentes pensamentos e vertentes analíticas; trânsito Ciência/Arte; tessitura teoria/empiria na construção do conhecimento; rigor criativo; liberdade metodológica de constituição de caminhos, com pluralidade de recursos e estratégias; e ecologia de Saberes.

Tanto para a pedagogia das artes cênicas, como para as demais áreas do conhecimento, os pressupostos epistemológicos construídos por Lima (2012) encontram-se implícitos nos documentos institucionais, podendo ser relacionados com teorias sobre currículo e com práticas pedagógicas.

\section{Teorias do currículo}

Silva (1999, p.21) considera que "de certa forma, todas as teorias pedagógicas e educacionais são também teorias sobre o currículo". Sob essa ótica, o currículo constitui uma importante peça para a regulação social inclusa na escolarização obrigatória.

Oscilando entre as intenções de obter ajuste social ou como uma via de transformação, os sistemas escolares administrariam suas práxis de acordo com a legislação educacional e com as expectativas que a sociedade deposita sobre os processos de ensinar e aprender. Na visão do autor, um currículo abarcaria métodos e conteúdo que evidenciam expectativas sociais, filosóficas e artísticas para as atividades de ensino-aprendizagem, além de ordenar cronologicamente essas atividades. 
Nas palavras de Silva (1999, p.30), as teorias sobre o currículo podem ser organizadas em três categorias: tradicionais, críticas e pós-críticas. Caracterizando-se da seguinte maneira:

As teorias críticas desconfiam do status quo, responsabilizando-o pelas desigualdades e injustiças sociais. As teorias tradicionais eram teorias de aceitação, ajuste e adaptação. As teorias críticas são teorias de desconfiança, questionamento e transformação radical. Para as teorias críticas o importante não é desenvolver técnicas de como fazer o currículo, mas desenvolver conceitos que nos permitam compreender o que o currículo faz.

As teorias pós-críticas, por sua vez, partilham da preocupação com as questões de poder ligadas ao saber. Caracterizando-se pelo multiculturalismo, evidenciam consideração a aspectos como gênero, sexualidade e etnia. Nas palavras de Silva (1999, orelha do livro):

\footnotetext{
Para as teorias pós-críticas, poder e conhecimento não se opõem, mas são mutuamente dependentes. Contrariamente às teorias críticas, as teorias pós-críticas do currículo não acreditam que exista um núcleo de subjetividade a ser libertado da alienação [...]. São as conexões entre significação, identidade e poder que passam, então, a ser enfatizadas. Para as teorias pós-críticas, o currículo está irremediavelmente envolvido nos processos de formação pelos quais nós nos tornamos o que somos. O currículo é uma questão de identidade e poder.
}

Cabe ressaltar que as três teorias podem conviver nos diferentes estabelecimentos de ensino e, às vezes, na mesma escola, variando de acordo com a área de conhecimento, com a etapa de seriação na qual os alunos se encontram ou com as filiações ideológicas dos docentes.

Na sequência procura-se identificar afinidades entre os pressupostos epistemológicos para as artes cênicas trazidos por Lima (2012) com as abordagens curriculares categorizadas por Silva (1999) em suas respectivas intenções pedagógicas.

Iniciando pelo pressuposto denominado como "rigor criativo", acredita-se que nas três teorias de currículo isso possa ocorrer pelo fato do termo rigor apresentar significados diferentes. Quando se caracteriza rigor como a exigência de reproduções artísticas orientadas por padrões estéticos pré-estabelecidos pode-se falar em currículo tradicional. Quando se traduz rigor pela oportunidade de ações conjuntas entre docentes e discentes para construções poéticas minuciosamente engendradas, pode-se falar em rigor na perspectiva de currículos críticos e pós-críticos. Ao considerar rigor como envolvimento e cuidado na elaboração de qualquer trabalho escolar por parte do aluno, visualiza-se uma ação intrínseca ao processo de aprender.

Já as teorias críticas parecem contempladas em seis dos dez pressupostos sistematizados por Lima, sendo estes: a construção processual do conhecimento, a contextualização cultural-política do conhecimento, o diálogo crítico/interlocução entre diferentes pensamentos e vertentes analíticas, a tessitura teoria/empiria na construção do conhecimento e a liberdade metodológica de constituição de caminhos, com pluralidade de recursos e estratégias. Em comum, esses pressupostos epistemológicos habitam um espaço escolar que promove questionamentos acerca das práticas artísticas. Um currículo de modelagem crítica busca proporcionar a in- 
clusão plena do estudante nos processos de ensino-aprendizagem sem a imposição de modelos estéticos. Quando as aulas de arte oportunizam a consciência de que podem haver padrões estéticos que traduzem diferentes funções sociais para a arte, leva em consideração a existência do aluno como sujeito poético capaz de posicionar-se criticamente em relação a esses padrões.

As teorias pós-críticas podem estar presentes na análise de todos os pressupostos epistemológicos quando acolhem a definição de ausência de uma única subjetividade e, portanto, da irrelevância de questionamentos e de embates ideológicos em relação às poéticas.

Empiricamente, acredita-se que a associação entre os pressupostos epistemológicos e as teorias do currículo possa instrumentalizar o docente diante do desafio de elaborar os documentos que a escola demanda. A escola é um lugar regido por normas e leis que vão além do aporte acadêmico e das identidades artísticas dos docentes. Elaborar os registros das práticas escolares de forma autoral, evidenciando de forma clara as especificidades das artes cênicas, contribui não somente para o reconhecimento da importância do seu trabalho, como também para a formação continuada de outros professores.

\section{Práticas escolares}

Antes de iniciar uma análise sobre a epistemologia das artes cênicas nas práticas escolares, apresenta-se alguns conceitos oriundos do campo específico da pedagogia. Presentes nos documentos específicos das escolas, eventualmente podem ser desconhecidos do licenciado em artes cênicas.

Os conceitos de "integração curricular, interdisciplinaridade e transdisciplinaridade", mais do que descreverem abordagens metodológicas, constituem narrativas para práticas escolares formais.

Nessa perspectiva, cabe descrever incialmente o que se entende aqui por "disciplina", para a seguir compreender seus desdobramentos. Partindo para uma busca semântica, encontrou-se no dicionário Michaelis (DISCIPLINA, 2008, p. 594) alguns dos significados para o substantivo disciplina, que a explicam como "a relação de subordinação do aluno para com o professor", "um ramo do conhecimento", "ciência", "matéria" e "obediência à autoridade".

A fim de buscar um sentido filosófico para disciplina, verificou-se que Abbagnano (2007, p.339) traz para o verbete o significado de "regramento" e de "categorização de sistemas de conhecimento", vinculando o termo disciplina ao contexto escolar. Portanto, a definição de disciplina equivaleria a "ciência", "ramo do conhecimento" e "matéria".

Nesse momento, o sentido de regramento por obediência não será pormenorizado. Trazendo o foco da discussão para disciplina com o significado de "categorização de sistemas de conhecimento", passa-se a seguir para as suas aplicabilidades. 


\section{Currículo integrado}

Na concepção de "currículo integrado", a disciplina pode ser entendida como uma expansão da área de conhecimento, que deixa de ser delimitada e estanque. Para Rodrigues (2007, p.3) "a integração curricular não pressupõe a inexistência da estrutura curricular por disciplinas [...]" O currículo integrado poderia ser caracterizado como "[...] resultante da confluência de diferentes conhecimentos disciplinares, sem fragmentá-los".

Sobre o mesmo conceito, Aires (2011, p.228) esclarece:

Integração Curricular está relacionada ao aspecto externo à disciplina, ou seja, à problemática. Consideramos que, sem ter isso definido, pode-se correr o risco de se estar apenas aderindo a um modismo, já que esses termos têm sido acolhidos com simpatia, tanto em documentos oficiais como em boa parte da literatura e, até, como uma espécie de marketing de algumas universidades e escolas privadas.

Quando se refere a "aspecto externo" e "problemática", Aires (2011) traz como exemplo a perspectiva da pedagogia baseada nos "Centros de Interesse", que se popularizaram no Brasil a partir da década de 1920, influenciando programas de ensino e práticas pedagógicas até então inéditas por permitir as expressões de espontaneidade do estudante nos processos de aprendizagem.

A pedagogia do "centro de interesse" contribui para a quebra da rigidez disciplinar no trato das áreas de conhecimento ao possibilitar o diálogo entre os saberes escolares e as problemáticas do cotidiano, sendo, portanto, análoga ao que se denomina integração curricular.

$\mathrm{Na}$ Base Nacional Comum Curricular (BNCC) para o Ensino Fundamental, a concepção de currículo integrado aparece como recomendação para os componentes curriculares de Educação Física (Brasil, 2018, p. 220) e de Matemática (Brasil, 2018, p. 274).

$\mathrm{Na}$ introdução desse documento, também aparece contemplada a perspectiva da integração curricular:

[...] cabe aos sistemas e redes de ensino, assim como às escolas, em suas respectivas esferas de autonomia e competência, incorporar aos currículos e às propostas pedagógicas a abordagem de temas contemporâneos que afetam a vida humana em escala local, regional e global, preferencialmente de forma transversal e integradora. (Brasil, 2018, p.19).

A noção de transversalidade, é vista acima como "temas contemporâneos que afetam a vida humana". Tais temas permaneceriam "ética, saúde, meio ambiente, orientação sexual, trabalho, consumo e pluralidade cultural" como aparecem na LDB $n \circ 9.394 / 96$ ? Sendo transversais poderiam ser integrados? De acordo com o que foi exposto sobre a metodologia do currículo integrado, os temas transversais poderiam ser tratados como "centros de interesse". Será que a transversalidade das temáticas sociais citadas acima não poderiam estar melhor contempladas em abordagens interdisciplinares e transdisciplinares? 


\title{
Interdisciplinaridade
}

Em publicações de diversas naturezas e objetivos, é possível identificar uma grande incidência do conceito de interdisciplinaridade. É apresentado também como conhecimento sistêmico ou holístico, em teorias ou práticas em todas áreas do conhecimento.

A interdisciplinaridade aparece como resposta para um excesso de especialização é objeto de discussão desde a década de 1960. Sem a pretensão de determinar uma única significação para interdisciplinaridade, apresenta-se inicialmente o que Lima (2016, p. xxxix) traz:

\begin{abstract}
$\mathrm{Na}$ atualidade a interdisciplinaridade tem sido palco de inúmeras discussões científicas e educacionais, tanto no exterior como no Brasil. É uma forma alternativa, complementar e inovadora de produzir conhecimentos. Opera nas fronteiras disciplinares e na religação de saberes, tendo como finalidade, dar conta de fenômenos complexos de diferentes naturezas. Essa dimensão epistemológica propiciou-lhe um desdobramento diferenciado no campo do conhecimento, na educação e nas artes em geral. Ela estabelece pontes entre diferentes níveis de realidade, diferentes lógicas e diferentes formas de produção de conhecimento.
\end{abstract}

$\mathrm{Na}$ análise do conceito de interdisciplinaridade que se viu anteriormente destaca-se o sentido de ponte referido pela autora. Sem negar as especificidades das disciplinas, o prefixo "inter" designa semanticamente um caráter de entrelaçamento e de posição intermediária ao radical que o acompanha.

Fazenda (2008) corrobora com a noção de que não existe interdisciplinaridade sem disciplinas. Segundo ela, nos anos de 1970, quando começou a pesquisar a interdisciplinaridade, havia uma intenção de acabar com as disciplinas em nome de uma "pseudo-integração". Mais do que forçar uma integração, a autora defende a ideia de que é necessário educar o olhar do professor para a totalidade de conhecimentos que essa articulação possa engendrar.

"Assim, na medida em que ampliamos a análise do campo conceitual da interdisciplinaridade surge a possibilidade de explicitação de seu espectro epistemológico e praxeológico" (Fazenda, 2008, p. 94).

Até que ponto o campo conceitual da interdisciplinaridade, inquestionável nas práticas artísticas, já pode ser documentado pelo professor de artes cênicas no contexto escolar? A formação pedagógica oportunizada pela licenciatura já o habilita para a identificação das características dos currículos e das abordagens metodológicas traduzindo os conteúdos das artes cênicas para as falas que circulam no território da escola?

O conceito de interdisciplinaridade aparece no texto introdutório da BNCC/Ensino Fundamental como uma decisão pedagógica institucional para elaborar currículos, dentre elas

[...] decidir sobre formas de organização interdisciplinar dos componentes curriculares e fortalecer a competência pedagógica das equipes escolares para adotar estratégias mais dinâmicas, interativas e colaborativas em relação à gestão do ensino e da aprendizagem. (Brasil, 2018, p. 16)

A proposta de interdisciplinaridade aparece ainda nas orientações para o ensino de língua inglesa (Brasil, 2018, p. 242) e de matemática (Brasil, 2018, p. 267). 


\section{Transdisciplinaridade}

A transdisciplinaridade, nas práticas e nas ideias pedagógicas, surge como uma retomada para abordar o conhecimento de uma forma oposta às inúmeras especializações ou fragmentações dos saberes.

Em 1994, no Convento da Arrábida, em Setúbal, Portugal, realizou-se o / Congresso Mundial de Transdisciplinaridade, onde foi produzida a "Carta da Transdisciplinaridade" que se ofereceu, naquele momento, a postular princípios para a construção de uma escola para o futuro.

Nicolescu (1999, não paginado) define a transdisciplinaridade a partir do que o prefixo "trans" indica, ao referir àquilo que está ao mesmo tempo entre as disciplinas, através das diferentes disciplinas e além de qualquer disciplina. O teórico aponta como objetivo para a transdisciplinaridade a compreensão do mundo presente, para o qual um dos imperativos é a unidade do conhecimento. Afirma que a transdisciplinaridade não pode ser considerada uma "nova disciplina", nem uma "hiperdisciplina" e reitera que a pesquisa disciplinar abastece e revigora-se pelo conhecimento transdisciplinar. Nesse sentido, as pesquisas disciplinares e transdisciplinares não seriam antagonistas, mas complementares.

Para Vasconcellos (2003, p.179), a definição de transdisciplinaridade contempla vários aspectos:

Em geral, para falar de transdisciplinaridade, fala-se antes de disciplinaridade, de multi ou pluridisciplinaridade, e de interdisciplinaridade. Disciplinaridade é usado para se referir à compartimentação do conhecimento do mundo entre as diversas disciplinas científicas. Multi ou pluridisciplinaridade refere-se a uma justaposição de disciplinas que não se comunicam, por exemplo, num curso em que se ministram disciplinas de diferentes áreas. Interdisciplinaridade, em geral, é usada para se referir à situação em que há algum tipo de interação onde duas ou mais disciplinas que se comunicam e que tentam aproximar seus discursos, ambicionando mesmo uma transferência de conhecimentos.

Na citação, a autora aborda a disciplinaridade e suas demais derivações como etapas anteriores ou implícitas ao conceito de transdisciplinaridade. Nessa perspectiva, oferece uma constatação axiomática de que há pontos de contatos entre todos os campos do conhecimento, buscando o que há de comum entre ciência, arte, filosofia e tradições sapienciais, o que implica necessariamente numa visão holística sobre os objetos de estudo.

Em relação aos pressupostos epistemológicos para as artes cênicas pode-se pensar que a transdisciplinaridade destoaria somente do aspecto de "construção processual do conhecimento" caso se compreendesse processo num sentido temporal. $\mathrm{Na}$ abordagem transdisciplinar para o conhecimento o sujeito se encontra envolvido de forma ubíqua em processos de ensino-aprendizagem que transcendem noções de espaço e tempo. 


\section{Epistemologia das artes cênicas: interfaces entre teoria pedagógica e prática escolar}

A fim de buscar interfaces entre as teorias pedagógicas desenvolvidas na academia e as práticas escolares descritas como abordagens metodológicas para o ensino, utilizou-se nesse trabalho a teoria de análise e categorização de currículos apresentados por Silva (1999) e o reconhecimento das práticas escolares que originam. Ao trazer os conceitos de currículo integrado, interdisciplinaridade e transdisciplinaridade para a organização de saberes, buscou-se visualizar de que forma as artes cênicas podem se fazer presentes na educação básica.

Aliando-se os estudos sobre currículo de Silva (1999) aos estudos sobre as abordagens metodológicas para as disciplinas escolares de Fazenda (2008), Vasconcellos (2003), Aires (2011), Lima (2016) e Rodrigues (2007), elaborou-se o quadro a seguir que pretende sintetizar o que foi até agora exposto:

\begin{tabular}{|c|c|c|}
\hline Epistemologia inventiva para as Artes Cênicas & \begin{tabular}{|l|}
$\begin{array}{l}\text { Teorias do } \\
\text { currículo }\end{array}$ \\
\end{tabular} & Práticas pedagógicas \\
\hline Construção processual do conhecimento & $\begin{array}{l}\text { Crítico } \\
\text { Pós-crítico }\end{array}$ & Currículo integrado \\
\hline Contextualização cultural-política do conhecimento & $\begin{array}{l}\text { Crítico } \\
\text { Pós-crítico }\end{array}$ & $\begin{array}{l}\text { Interdisciplinaridade } \\
\text { Transdisciplinaridade }\end{array}$ \\
\hline $\begin{array}{l}\text { Perspectiva da incerteza e da busca na aventura do } \\
\text { conhecer: lógica da descoberta, em detrimento da } \\
\text { lógica da prova }\end{array}$ & Pós-crítico & $\begin{array}{l}\text { Currículo integrado } \\
\text { Interdisciplinaridade } \\
\text { Transdisciplinaridade }\end{array}$ \\
\hline $\begin{array}{l}\text { Ótica da complexidade, a exigir transdisciplinaridade e } \\
\text { articulação de saberes }\end{array}$ & Pós-crítico & Transdisciplinaridade \\
\hline $\begin{array}{l}\text { Diálogo crítico/interlocução entre diferentes } \\
\text { pensamentos e vertentes analíticas }\end{array}$ & $\begin{array}{l}\text { Crítico } \\
\text { Pós-crítico }\end{array}$ & $\begin{array}{l}\text { Currículo integrado } \\
\text { Interdisciplinaridade }\end{array}$ \\
\hline Trânsito Ciência/Arte & Pós-crítico & Transdisciplinaridade \\
\hline $\begin{array}{l}\text { Tessitura teoria/empiria na construção do } \\
\text { conhecimento }\end{array}$ & $\begin{array}{l}\text { Crítico } \\
\text { Pós-crítico }\end{array}$ & $\begin{array}{l}\text { Currículo integrado } \\
\text { Interdisciplinaridade } \\
\text { Transdisciplinaridade }\end{array}$ \\
\hline Rigor criativo & $\begin{array}{l}\text { Tradicional } \\
\text { Crítico } \\
\text { Pós-crítico }\end{array}$ & $\begin{array}{l}\text { Currículo integrado } \\
\text { Interdisciplinaridade } \\
\text { Transdisciplinaridade }\end{array}$ \\
\hline $\begin{array}{l}\text { Liberdade metodológica de constituição de caminhos, } \\
\text { com pluralidade de recursos e estratégias }\end{array}$ & $\begin{array}{l}\text { Crítico } \\
\text { Pós-crítico }\end{array}$ & $\begin{array}{l}\text { Currículo integrado } \\
\text { Interdisciplinaridade } \\
\text { Transdisciplinaridade }\end{array}$ \\
\hline Ecologia de saberes & Pós-crítico & $\begin{array}{l}\text { Currículo integrado } \\
\text { Transdisciplinaridade }\end{array}$ \\
\hline
\end{tabular}

Quadro 1 - Interfaces entre epistemologia, currículo e prática pedagógica no contexto da educação básica. Fonte: Autoria própria, 2018. 
Este exercício de comparação entre as interfaces que podem compor discursos institucionais e acadêmicos motivam a análise de um cenário onde cabe trazer de que maneira é possível identificar os conceitos citados nesse artigo junto aos textos que compõem as legislações educacionais brasileiras. Ao questionar de que maneira os documentos oficiais brasileiros têm acompanhado as teorias sobre os processos de ensino-aprendizagem objetiva-se também identificar como o discurso da lei tem se efetivado enquanto prática nas escolas.

\section{O discurso da legislação}

A sistematização de saberes para o estudo das artes cênicas na escola tem sido abordada de diferentes modos nas últimas formatações das Leis de Diretrizes e Bases para a educação brasileira. Por considerar que essas diferenças constituem alterações que provocam mais do que ajustes nos tempos e espaços para a aprendizagem, cabe identificar de que forma essas configurações impõem-se como epistemologia para as artes cênicas na escola.

Nesse sentido, procurou-se pesquisar textos de leis federais que trazem determinações ou metodologias específicas para o ensino-aprendizagem em arte.

Partindo da leitura das Leis de Diretrizes e Bases da Educação Nacional, a LDB no 5.692, promulgada em 11 de agosto de 1971, e a LDB nㅇ 9.394, de 20 de dezembro de 1996 constata-se que o ensino de arte consta como disciplina obrigatória.

No Artigo 7으, do Capítulo I, da LDB no 5692/71, aparece um único texto que menciona de forma específica a arte na escola

Será obrigatória a inclusão de Educação Moral e Cívica, Educação Física, Educação Artística e Programas de Saúde nos currículos plenos dos estabelecimentos de $1^{\circ}$ e $2^{\circ}$ graus, observado quanto à primeira o disposto no Decreto-Lei n. 369, de 12 de setembro de 1969 .

Já o texto a seguir, pode ser lido no volume 6 do Parâmetro Curricular Nacional (PCN) que é dedicado ao ensino de Arte

Em 1971, pela Lei de Diretrizes e Bases da Educação Nacional, a arte é incluída no currículo escolar com o título de Educação Artística, mas é considerada "atividade educativa" e não disciplina. A introdução da Educação Artística no currículo escolar foi um avanço, principalmente se se considerar que houve um entendimento em relação à arte na formação dos indivíduos, seguindo os ditames de um pensamento renovador. No entanto, o resultado dessa proposição foi contraditório e paradoxal. Muitos professores não estavam habilitados e, menos ainda, preparados para o domínio de várias linguagens, que deveriam ser incluídas no conjunto das atividades artísticas (Artes Plásticas, Educação Musical, Artes Cênicas). (PCN, v.6,1997, p.24)

Ao estabelecer uma comparação entre essas duas legislações no que se refere a natureza da disciplina Arte, Subtil (2009, p.191) enfatiza que de 1971 para 1996 há um deslocamento "em prol da definição da Arte como um campo de conhecimento com estatuto epistemológico equivalente ao de qualquer outra área" quando passa da denominação de "Educação artística" para "Ensino de Arte". 
Essas conquistas, entretanto, ainda não estariam consolidadas na medida que a questão da obrigatoriedade para o ensino de arte na educação básica permaneceria como matéria alterada pelas leis de $n \circ 12.287$ de 13 de julho de 2010 e pela $n \circ 13.415$ de 16 de fevereiro de 2017, que modificaram parte do texto da LDB no 9.394.

No texto da LDB de 1996 pode-se ler no Artigo 26, "§20 O ensino da arte, especialmente em suas expressões regionais, constituirá componente curricular obrigatório da educação básica".

$\mathrm{Na}$ alteração feita em 2010, lê-se o mesmo artigo com a seguinte redação: "§2o O ensino da arte constituirá componente curricular obrigatório, nos diversos níveis da educação básica, de forma a promover o desenvolvimento cultural dos alunos".

E em 2017, muda novamente: "§o 20 O ensino da arte, especialmente em suas expressões regionais, constituirá componente curricular obrigatório da educação básica".

As expressões "obrigatório" e "componente curricular" podem parecer consolidar todos os movimentos empreendidos pelos pesquisadores e docentes que se dedicam aos processos de ensino de Arte. Porém, é preciso destacar que os aparentemente pequenos ajustes visualizados nesses textos podem resultar em retrocessos no que se consideraria como diversidade cultural e como direito para aprender sobre todos os campos dos saberes. Além de especular o motivo de inclusões e retiradas dos termos "expressões regionais" e "nos diversos níveis", cabe também questionar como a docência na educação básica poderá unir tais exigências aos métodos e recursos disponíveis em cada uma das escolas brasileiras.

Talvez uma forma de responder a esses questionamentos seja através de textos que trazem de forma específica princípios epistemológicos para as artes cênicas oriundos das legislações, das pesquisas acadêmicas e das publicações especializadas.

No ano de 1978, o Ministério da Educação e Cultura do Brasil publicou um texto denominado "O artigo 7이 da Lei 5692/71 no ensino de 2ำ grau". Ao traçar "considerações gerais para a educação artística" (p.61), a publicação apresenta como "sugestões para operacionalização" partir do "corpo como agente do autoconhecimento e conhecimento do mundo exterior" (p.64), trazendo o "bom domínio do corpo" como meio para a identificação de "FORMA - volume, peso, textura, espaço. SOM - ritmo, voz, pulsação, respiração. MOVIMENTO - andar, relaxar, deitar, saltar" (p.64), identificação essa que se estenderia a outras formas de expressão, para que o aluno "o faça corretamente". Ainda na página 64, destaca-se a afirmação de que "as linguagens criativas, hoje, não mais permitem uma classificação rígida e estática. $O$ criador, ao rever o mundo, sabe que as qualidades cinéticas, auditivas e visuais estão presentes em toda forma". Mais adiante é possível ler que

[...] a escola tentará revitalizar estas linguagens no seu conteúdo profundo e significativo. Assim, por exemplo, o professor compreenderá que numa improvisação cênica, está presente a expressão plástica, a música, a matemática, a expressão corporal, a dicção, a ciência; e a cada um desses elementos se somam forma, som e movimento. Ao se envolver no complexo significado das suas próprias experiências, o aluno estará apto para compreender a linguagem contemporânea. (1978, p.66) 
Será que a ideia da hibridização das linguagens artísticas do professor polivalente de 1978 poderia corresponder às concepções de interdisciplinaridade e de transdisciplinaridade do século XXI? Será que com o aporte pedagógico oferecido nos cursos de Educação artística em 1978 um professor conseguiria tornar complexa suas práticas pedagógicas a ponto de oportunizar que o aluno pudesse operar com a lógica da complexidade?

Os Parâmetros Curriculares Nacionais publicados em 1997, procuraram recuperar de forma sucinta o que apresentam como um "Histórico do ensino de Arte no Brasil e perspectivas". Ao descreverem a educação artística praticada entre os anos 1970 e 1980, afirmam que:

[...] os antigos professores de Artes Plásticas, Desenho, Música, Artes Industriais, Artes Cênicas e os recém-formados em Educação Artística viram-se responsabilizados por educar os alunos (em escolas de ensino médio) em todas as linguagens artísticas, configurando-se a formação do professor polivalente em Arte. Com isso, inúmeros professores deixaram as suas áreas específicas de formação e estudos, tentando assimilar superficialmente as demais, na ilusão de que as dominariam em seu conjunto. A tendência passou a ser a diminuição qualitativa dos saberes referentes às especificidades de cada uma das formas de arte e, no lugar destas, desenvolveu-se a crença de que bastavam propostas de atividades expressivas espontâneas para que os alunos conhecessem muito bem música, artes plásticas, cênicas, dança, etc. $(1997$, p.24)

Em resposta a diminuição qualitativa das especificidades de cada uma das linguagens e da dificuldade em diferenciar polivalência de interdisciplinaridade (ou transdisciplinaridade) surgiram ações que buscavam mobilizar os profissionais da arte. A partir da década de 1980 multiplicam-se pelo Brasil eventos de caráter acadêmico e de categorias profissionais, organizados por instituições públicas e privadas, promovendo discussões sobre a formação de professores, trazendo questões relacionadas a suas competências e ao seu papel específico dentro da escola.

Ao lembrar da importância que a Arte representa no desenvolvimento de cada estudante o PCN Arte traz o seguinte:

O conhecimento da arte abre perspectivas para que o aluno tenha uma compreensão do mundo na qual a dimensão poética esteja presente: a arte ensina que é possível transformar continuamente a existência, que é preciso mudar referências a cada momento, ser flexível. Isso quer dizer que criar e conhecer são indissociáveis e a flexibilidade é condição fundamental para aprender. O ser humano que não conhece arte tem uma experiência de aprendizagem limitada, escapa-lhe a dimensão do sonho, da força comunicativa dos objetos à sua volta, da sonoridade instigante da poesia, das criações musicais, das cores e formas, dos gestos e luzes que buscam o sentido da vida. (1997, p. 19)

Ainda que atravessada por uma utopia quase ingênua, essa descrição parece contemplar o clamor dos educadores brasileiros que saíam de um período de ditadura militar e pretendiam resgatar nos espaços escolares o direito de oferecer ações educativas de maneira coerente com a sua formação profissional e com suas concepções artísticas. Essa forma de ensinar arte na escola de educação básica, garantida e fomentada em um documento como o PCN de 1997 parece acolher aos currículos de modelagem 
crítica quando traz a ideia de transformação da existência a partir do conhecimento e da criação. Ao referir a potência dos objetos de estudo das diferentes linguagens artísticas, esse documento reconhece as artes visuais, a dança, a música e o teatro como áreas do conhecimento.

Ao referir-se ao componente curricular Arte, a BNCC/EF aponta:

Em síntese, o componente Arte no Ensino Fundamental articula manifestações culturais de tempos e espaços diversos, incluindo o entorno artístico dos alunos e as produções artísticas e culturais que lhes são contemporâneas. Do ponto de vista histórico, social e político, propicia a eles o entendimento dos costumes e dos valores constituintes das culturas, manifestados em seus processos e produtos artísticos, o que contribui para sua formação integral. (Brasil, 2018, p. 194).

Para viabilizar o que a BNCC/EF (2018, p.192) traz como "formação integral", cabe averiguar o trecho no qual propõe dimensões para o conhecimento que não se configuram como eixos temáticos e nem como metodologias, mas sim o modo como a experiência artística se processa em sua singularidade. Essas dimensões são descritas como "linhas maleáveis que se interpenetram, constituindo a especificidade da construção do conhecimento em Arte na escola"(p.192-193). As seis dimensões definem-se como "criação" (o fazer artístico); "crítica" (impressões que impulsionam os sujeitos em direção a novas compreensões); estesia (a experiência sensível); expressão (exteriorizar e manifestar criações subjetivas por meios artísticos); "fruição" (deleite, prazer, estranhamento, sensibilidade); "reflexão" (construção de argumentos e ponderações sobre as fruições) e se fariam presentes em todas as linguagens artísticas.

$\mathrm{Na}$ versão da BNCC pesquisada para a escrita desse artigo, as linguagens de Artes visuais, Dança, Música e Teatro aparecem também denominadas como "uma unidade temática que reúne objetos de conhecimento e habilidades articulados às seis dimensões" (p.196), acrescidas ainda de uma denominada "Artes Integradas" que, ao que parece, poderia significar uma abordagem integrada, interdisciplinar ou transdisciplinar, quando se propõe a explorar "relações e articulações entre as diferentes linguagens e suas práticas, inclusive aquelas possibilitadas pelo uso das novas tecnologias de informação e comunicação".

Unidade temática? Artes Integradas? E a consideração das linguagens artísticas com suas epistemologias próprias? O que se propõe será mesmo a transformação da aprendizagem em códigos alfanuméricos (vide páginas 204 a 209) usados para mensurar o conhecimento de cada aluno quanto às "seis dimensões"? 


\section{Considerações finais}

Após essa breve análise apresentada ao longo desse texto, acredita-se que a pedagogia das Artes Cênicas se encontre cercada por paradoxos que constituem desafios a todos os que se dispõem a pensar sobre o assunto.

O paradoxo inicial dá conta da incidência paralela das diferentes categorias de currículos. Mesmo que originados em diferentes tempos históricos e lugares, os currículos tradicionais, críticos e pós-críticos, coexistem evidenciando os interesses institucionais quanto a sua aplicabilidade. Ao deparar-se com esses diferentes desenhos curriculares cada professor de artes cênicas é capaz de elaborar e registrar seu material de trabalho de modo autoral, circulando com desenvoltura entre as teorias pedagógicas?

Um segundo paradoxo indica que apesar das práticas artísticas contemporâneas apresentarem processos de hibridização similares com o que se preconiza a partir da "ótica da complexidade, a exigir transdisciplinaridade e articulação de saberes", os processos formativos em Arte aos olhos da BNCC, por exemplo, caminham em outra direção. Causa estranhamento que esteja em processo de implementação uma base curricular que se propõe a tornar homogêneo o estudo da arte em todo o território nacional. Essa homogeneidade nega pressupostos tão significativos para aprendizagens no campo artístico, como a "perspectiva da incerteza e da busca na aventura do conhecer: lógica da descoberta, em detrimento da lógica da prova" e "liberdade metodológica de constituição de caminhos, com pluralidade de recursos e estratégias". Uma padronização de objetivos e métodos para as ações de ensino-aprendizagem em arte vai de encontro não somente ao que se conquistou no território das artes cênicas da escola, mas em todo o fazer artístico contemporâneo, impedindo que se construam identidades artísticas individuais e coletivas.

O paradoxo três trata da desconsideração da "ecologia dos saberes" em detrimento da priorização das disciplinas que compõem o conjunto de provas que mensuram a qualidade de ensino no Brasil. A "contextualização cultural e política do conhecimento" inviabiliza-se e o caráter de hierarquização dos saberes prossegue evidente. Se a educação em arte se beneficiou com o reconhecimento das suas linguagens como área de conhecimento, enfrenta agora um novo caminho que busca as interlocuções entre o ser "área de conhecimento" sem deixar de ser interdisciplinar e transdisciplinar por excelência.

Diante desse cenário, acredita-se que se possa enfrentar os retrocessos epistemológicos potencializando o trabalho docente através da apropriação reflexiva dos discursos que circulam na escola. Espera-se que ao modelar seus documentos institucionais, o professor de artes cênicas encontre espaços para o exercício da autoria podendo buscar subsídios para argumentar sobre a relevância do seu trabalho. 


\section{Referências}

ABBAGNANO, Nicola. Dicionário de filosofia. São Paulo: Martins Fontes, 2007.

AIRES, Joanez Aparecida. Integração curricular e interdisciplinaridade: sinônimos? Educação \& Realidade, Porto Alegre, v. 36, n. 1, p. 215-230, jan./abr. 2011. Disponível em: <http://www.seer.ufrgs.br/index.php/educacaoerealidade/article/view/ 9930/11573>. Acesso em: 27 fev. 2018.

BRASIL. Lei $n$ ㅇ 13.415, de 16 de fevereiro de 2017. Altera a Lei no 9.394 de 20 de dezembro de 1996 que estabelece as diretrizes e bases da educação nacional. Disponível em: <http://www.planalto.gov.br/ccivil_03/_Ato2015-2018/2017/Lei/L13415. htm\#art3> Acesso em: 30 jan. 2019.

BRASIL. Lei $n^{\circ}$ 5.692, de 11 de agosto de 1971. Fixa diretrizes e bases para o ensino de 1ํ e 2 ㅇaus, e dá outras providências. Disponível em: <http://www2.camara.leg.br/ legin/fed/lei/1970-1979/lei-5692-11-agosto-1971-357752-publicacaooriginal-1-pl. html >. Acesso em: 25 jan. 2019.

BRASIL. Lei no 9.394, de 20 de dezembro de 1996. Estabelece as diretrizes e bases da educação nacional. Disponível em: <http://www2.camara.leg.br/legin/fed/

lei/1996/lei-9394-20-dezembro-1996-362578-publicacaooriginal-1-pl.html>. Acesso em: 10 mar. 2018.

BRASIL. Ministério da Educação. Base Nacional Comum Curricular: educação é a base. Brasília, DF: Ministério da Educação, 2018. Disponível em: <http://basenacionalcomum.mec.gov.br/wp-content/uploads/2018/04/BNCC_

19mar2018_versaofinal.pdf>. Acesso em: 02 jun. 2018.

BRASIL. Secretaria de Educação Fundamental. Parâmetros curriculares nacionais: arte. Brasília, DF, 1997. Disponível em: <http://portal.mec.gov.br/seb/ arquivos/pdf/livro06.pdf>. Acesso em: 10 mar. 2018.

DISCIPLINA. In: MICHAELIS: dicionário escolar da língua portuguesa. 3. ed. São Paulo: Melhoramentos, 2008. p. 594.

FAZENDA, Ivani Catarina Arantes. Interdisciplinaridade e transdisciplinaridade na formação de professores. Ideação: revista do Centro de Educação e Letras, Foz do Iguaçu, PR, v. 10, n. 1, p. 93-103, 2008. Disponível em: <http://saber.unioeste.br/ index.php/ideacao/article/view/4146/3191>. Acesso em: 27 fev. 2018.

FREITAS, Lima de; MORIN, Edgar; NICOLESCU, Basarab. Carta da transdisciplinaridade. Setúbal: CETRANS, 1994. Disponível em:<http://cetrans.com.br/assets/docs/ CARTA-DA-TRANSDISCIPLINARIDADE1.pdf>. Acesso em: 08 jun. 2018. 
LIMA, Sonia Regina Albano de. Relato da presidente da ANPPOM para o ARJ. Art Research Journal ,Brasil, v. 3, n. 3, p. xxxvii-xli, 2016. Disponível em: <https://periodicos. ufrn.br/artresearchjournal/article/view/12076/8416>. Acesso em: 10 mar. 2018.

LIMA, Wladilene de Sousa. Epistemologias inventivas na pesquisa em artes cênicas no Pará. In: CONGRESSO DA ABRACE, 7., 2012, Porto Alegre. Anais... Porto Alegre: ABRACE, 2012.Disponível em: <http://www.portalabrace.org/viicongresso/ completos/territorios/Wlad_LIMA_Epistemologias_Inventivas_na_Pesquisa_em_Artes_C_nicas_no_Par__.pdf>. Acesso em: 14 jan. 2019.

NICOLESCU, Basarab. O manifesto da transdisciplinaridade. São Paulo: Triom, 1999.

RODRIGUES, Marilce da Costa Campos. A integração curricular na prática pedagógica dos docentes dos anos iniciais em uma escola organizada em ciclos de formação humana. In: ASSOCIAÇÃO NACIONAL DE PÓS-GRADUAÇÃO E PESQUISA EM EDUCAÇÃO. Reunião anual, 30., 2007, Caxambu, MG. Anais... Rio de Janeiro: ANPED, 2007. Disponível em: <http://www.anped.org.br/sites/default/

files/gt12-2938-int.pdf>. Acesso em:01 jun. 2018.

SILVA, Tomaz Tadeu da. Documentos de identidade: uma introdução às teorias do currículo. Belo Horizonte: Autêntica, 1999.

SUBTIL, Maria José Dozza. Práxis Educativa, Ponta Grossa, v.4, n.2, p.185-194, jul.-dez. 2009. Disponível em: http://www.revistas2.uepg.br/index.php/praxiseducativa/article/view/716/656 Acesso em: 25 jan.2019.

TESSER, Gelson João. Principais linhas epistemológicas contemporâneas. Educar em Revista, Curitiba, n. 10, p. 91-98, 1994.Disponível em: <http://www.scielo.br/pdf/ er/n10/n10a12.pdf>. Acesso em: 02 jun. 2018.

VASCONCELLOS, Maria José de. Pensamento sistêmico: o novo paradigma da ciência. Campinas, SP: Papirus, 2003.

Recebido em: 04/07/2018

Aprovado em: 10/02/2019 